\title{
Safe the Planet: Facemasks Disposal Due to Covid-19 Pandemics
}

Siti Hafsyah Idris, Muhammad Azril Bin Roslan, Hazwani Binti Hassan, Khairunnisa Binti Azman and Mazliyana Binti Malek @ Maaroff

To Link this Article: http://dx.doi.org/10.6007/IJARBSS/v11-i11/11207

DOI:10.6007/IJARBSS/v11-i11/11207

Received: 12 September 2021, Revised: 14 October 2021, Accepted: 26 October 2021

Published Online: 20 November 2021

In-Text Citation: (Idris et al., 2021)

To Cite this Article: Idris, S. H., Roslan, M. A. Bin, Hassan, H. B., Azman, K. B., \& Maaroff, M. B. M. @. (2021). Safe the Planet: Facemasks Disposal Due to Covid-19 Pandemics. International Journal of Academic Research in Business and Social Sciences, 11(11), 1317-1326.

Copyright: (c) 2021 The Author(s)

Published by Human Resource Management Academic Research Society (www.hrmars.com)

This article is published under the Creative Commons Attribution (CC BY 4.0) license. Anyone may reproduce, distribute, translate and create derivative works of this article (for both commercial and non-commercial purposes), subject to full attribution to the original publication and authors. The full terms of this license may be seen at: http://creativecommons.org/licences/by/4.0/legalcode

Vol. 11, No. 11, 2021, Pg. 1317 - 1326

Full Terms \& Conditions of access and use can be found at http://hrmars.com/index.php/pages/detail/publication-ethics 


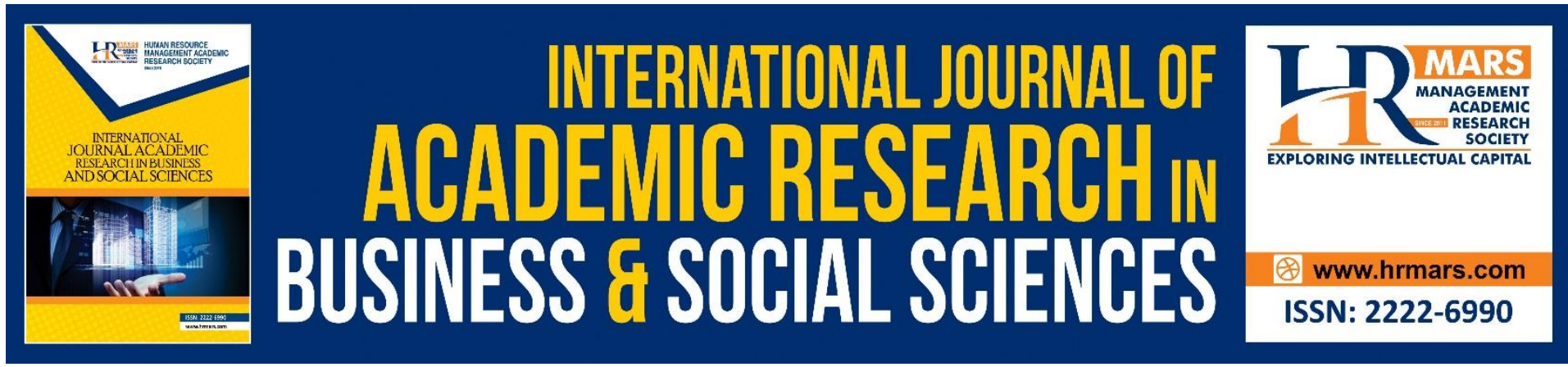

\title{
Safe the Planet: Facemasks Disposal Due to Covid-19 Pandemics
}

\section{Siti Hafsyah Idris, Muhammad Azril Bin Roslan, Hazwani Binti Hassan, Khairunnisa Binti Azman and Mazliyana Binti Malek @ Maaroff}

Faculty of Law, Universiti Teknologi MARA, Ministry of Health Malaysia, Universiti Sultan Zainal Abidin

Email: sitihafsyah@uitm.edu.my, azril004@uitm.edu.my,dr_hazwani@moh.gov.my, khairunnisa.a@moh.gov.my, mazliyanamalek@unisza.edu.my

\begin{abstract}
Globally, the ongoing COVID-19 pandemic has resulted in a massive increase in the consumption of single-use face masks used for personal protective equipment (PPE) to prevent virus transmission. However, improper management of such materials poses a new form of plastic pollution to the sustainability of the environment. This article investigates the public's awareness, particularly amongst the immigrant workers on the methods of facemasks disposal during the pandemic to educating foreigners or immigrant in addressing the negative environmental impact of waste disposal. Furthermore, standardisation, procedures, guidelines, and strict implementation of facemasks management concerning COVID-19, community habitats, and public areas should be carefully considered to mitigate pandemic risks in transmitting the virus. Proper facemasks disposal effectively controls infection sources as well as ensure environmental sustainability.
\end{abstract}

Keywords: Facemasks, Disposal, COVID-19, Environmental Sustainability, Awareness.

\section{Introduction}

Numerous countries have taken various precautions and measures in response to the emergence of a new coronavirus, officially known as COVID-19, which the World Health Organization (WHO) has declared a public health emergency of international concern (PHEIC) (Fadare \& Okoffo, 2020). Woldometer provides that as of September 27th, 2021, there were over 219 million confirmed cases across 219 countries and territories, with a death toll of over 2 million; this number is still rising.

Personal protective equipment (PPE) such as facemasks, medical gloves, aprons, and disposable protective cloths have been recommended for frontline medical workers (e.g., doctors, nurses, caregivers, etc.) and other people handling COVID-19 patients. In addition, residents are advised to use facemasks in public places to protect themselves from the germs. Since these recommendations were made, the COVID-19 pandemic has produced and used billions of personal protective equipment (PPE) every day. There is a large amount of used 
personal protective equipment (PPE) that is considered infectious waste and must be treated as medical or hazardous waste because COVID-19 can survive on the surface of objects for several hours to several days (Kampf et al., 2020). If improperly handled, they can have negative consequences for the environment and human health.

Mask usage was not universally viewed as positive, despite the multifaceted benefits of face masks (Chu et al., 2020). However, data from World Health Organization even official sites criticised the use of face masks, for example, because people might incorrectly use them, increase hazardous hand-face contacts when using masks. Outside the health sector, wearing professional masks was seen as problematic due to unsecure logistics, unused storage, and "unnecessary costs".

Because of this, beaches and other public areas have been significantly polluted. Also, most people didn't wear face masks until early 2020. Wearing masks was thus initially unpopular in Europe, whereas they were widely worn in Asian communities (Carbon, 2021). Individual mask-wearing behaviour has recently been linked to personality traits. Importantly, the (descriptive) social norm has not yet been highlighted. In this case, understanding pandemic psychology is crucial. In order to change behaviour, a psychological perspective is required. Hence, for mask-wearers, the social norm may provide a psychological explanation.

While the COVID-19 pandemic has not yet subsided in Malaysia, face masks are the mandatory accessories worn when leaving the house. Mandating face masks in public places simultaneously raises another concern about proper handling and disposal of the face masks used. Unbeknownst to us, the non-proper disposal of face masks will result in environmental pollution as face masks cannot be recycled (Torres \& Torre, 2021). Subsequently, the face mask will end up in the surrounding environment polluting the rivers or oceans, later harming the ecosystems and aquatic species. (Sangkham, 2020). Notably, the increased production and consumption of personnel protective equipment items around the world to combat the spread of coronavirus adds to the already-existing concern about plastic pollution and its effects on the environment and wildlife if these items are not properly disposed of.

The discovery of various types and colours of facemasks in a Hong Kong Ocean was reported in February 2020 by Oceans Asia, a marine pollution research organisation (Fadare \& Okoffo, 2020). Hence, to ensure that all residents in Malaysia, whether citizens or non-citizens have the right to a clean and conducive environment in accordance with Article 8 of the Federal Constitution, which emphasises equality, this research is seen to be able to recognise and achieve the aim by educating foreigners or immigrant on the proper handling and disposal of face mask. As a result of this phenomenon, Malaysia is undergoing a transition in terms of solid waste management due to the rapid generation of solid waste. Indeed, Malaysia has implemented a solid waste management policy and legislation. The passage of the Solid Waste Management and Public Cleansing Act (Act 672) has resulted in a sea change in Malaysia's solid waste management. Besides, improper handling of face masks disposal is an environmental violation can be defined as illegal actions which directly harm the environment as stated under the EQA 1974 which primarily relates to the prevention, abatement, control of pollution and enhancement of the environment. 
This paper is based on the research for an environmental disposal handling awareness education program among foreigners in Malaysia which was implemented with several objectives. First, to ensure that communities can live together in a clean and healthy environment based on principles in environmental ethics which emphasises moral obligations in providing a conducive environment.

Second, to ensure the necessities of life such as water and air are always clean and continuous for the sake of future generations. Third, to reduce the dangers and risks of infection because a clean environment can indirectly reduce the breeding grounds of mosquitoes, rodents, and flies that are disease-carrying agents. Fourth, to maintain a clean and conducive environment so that the community can do recreational activities with the family.

Fifth, to educate the foreign worker's community in Malaysia on proper handling and disposal of face masks, which indirectly contribute to preserving the environment for the sustainability of life. Lastly, to assist environmental protection through community involvement, especially in educating the community on the importance of looking after a sustainability of the environment by adhering to the existing law on waste disposal.

\section{Methodology}

Due to the fact that Malaysia is currently experiencing another wave of Covid-19 pandemic, it is nearly impossible to approach all citizens to provide education concerning the issues on face mask pollution directly. Therefore, a specific group or community has been selected for the information sharing and knowledge transfer program to be carried on. Furthermore, to overcome the barrier of educating all citizens in Malaysia on the issue, a documentary and educational video on proper handling and disposing of face masks will be produced, later shared with the public via social media.

\section{Pre-program Preparation}

Before the information sharing and knowledge transfer session related to proper handling and disposal of face masks are carried out on the foreign workers or immigrant community in Malaysia, preparation in terms of information to be conveyed is discussed in detail. Program committee members established with different job scopes. Before the project's commencement, the team had produced a concise storyline to ensure smooth workflow before the camera started rolling.

\section{Information Sharing and Knowledge Transfer Session}

The researchers visited the filming location beforehand to understand the location they were working with fully. The activities were conducted over multiple areas around Kuala Lumpur, where foreign workers or immigrant communities expected to be approached easily.

Visiting locations beforehand enables the researchers to preview each "scene" and update the shortlist and storyboard with actual, accurate pictures. The designated locality for video recording was KL Sentral, KLCC, Bukit Bintang, and Pavilion, Malaysia.

Throughout the session, strict Standard Operating Procedures (SOP) as required by the Ministry of Health (MOH) \& the Malaysian National Security Council (MKN) was followed. 
Generally, the Information Sharing and Knowledge Transfer Sessions on the foreign workers or immigrant communities were conducted as follows:

Researchers have approached the foreign workers or immigrants (Respondents) to explain the program briefly and obtain their consent for video recording. Then, QR Code via My Sejahtera apps showed to the respondents for them to scan. The QR Code consisted of details on respondent names and phone numbers which were considered consent for their project participation.

The researchers conducted a question and sharing Sessions to obtain foreign workers and immigrants' understanding of proper handling and disposal of face masks.

Researchers shared their knowledge and demonstrated the proper handling and disposal of face masks to the respondent. Besides, researchers also emphasise face mask pollution as one of the environmental hazards in the making if not disposed of properly. The respondents were then asked for re-demonstrate the proper face mask disposal procedure before the researchers to determine their understanding of the issue.

Token of appreciation is given to the respondents after the session is completed.

Researchers have also noted various issues experienced by the foreigner or immigrant community concerning face mask usage.

\section{Production of Educational Video}

The video encompassed three parts: First, the documentary related to the "new norm" face mask pollution, containing the impactful "Face Mask pollution" pictures, pertinent findings, and relevant data. The second part includes video recording on the program implementation, information sharing, and knowledge transfer sessions among the foreign worker's community or immigrants. Additionally, education on the type of face mask, handling, and properly disposing of face masks were materialised in the video, narrated accordingly by the researchers. Lastly, the video ended by showing the outcome, finding and conclusion of the program, and acknowledging those involved throughout program implementation.

The completed documentary video was uploaded to the social media channel and shared by the researchers on their social media platform, primarily via Facebook or Instagram. The objective of uploading this video on social media sites is to make it easy for the public to browse, indirectly exposing the importance of proper handling and face mask disposal to ensure environmental sustainability.

\section{Results}

During Information Sharing and Knowledge Transfer Sessions, 20 foreign workers and immigrants were approached; however, only six were willing to participate in the session. Even so, the session was only conducted on 5 of the respondents due to unforeseen circumstances. The findings from the information sharing session as well as from our observation are as per summarised in Table 1.0 below: 


\begin{tabular}{|l|l|l|}
\hline Bil. & \multicolumn{1}{|c|}{ Detail } & Number of immigrants \\
\hline 1. & $\begin{array}{l}\text { Improper use of mask } \\
\text { (Mask do not fully cover the respective areas needed } \\
\text { mask was put under the chin, using dirty or recycle mask }\end{array}$ & 3 \\
\hline 2. & $\begin{array}{l}\text { Proper use of mask } \\
\text { (Mask covering the respective areas) }\end{array}$ & 2 \\
\hline 3. & $\begin{array}{l}\text { Unhygienic hand } \\
\text { (Immigrants are not equipped with hand sanitizers as wel } \\
\text { not practicing proper hand hygiene) }\end{array}$ & 3 \\
\hline 4. & Language barrier & 4 \\
\hline
\end{tabular}

Table 1.0 Number of Immigrants and Their Understanding of Mask Handling

It can be further illustrated in the graph below



\section{Discussion}

As of August 11, 2021, 89 percent of Malaysian respondents reported wearing face masks in public spaces during the COVID-19 outbreak, up from 55\% on February 24, 2020. COVID-19 cases are increasing in Malaysia now. To halt the virus's spread, the government declared a state of emergency in all states hardest hit by the pandemic. Based on information obtained from the Ministry of Health Malaysia $(\mathrm{MOH})$ data, it was found that there was a significant increase in cases of Covid-19 infection among foreign workers or immigrants in Malaysia. Among the main contributors to this problem is the lack of awareness of the importance of maintaining cleanliness, including education on face mask disposal, which involves the use, storage, and disposal of face masks that have been used. The reuse of disposable face masks was identified as one of the causes of the epidemic spreading faster among foreign workers. Additionally, the incorrect procedure of face mask removal or disposal may also lead to the faster spread of the epidemic apart from culminating in the emergence of "new norm" environmental pollution. 
Wearing a face mask in public areas has been mandatory from August 1st, 2020, which has caused a spike in face masks usage. Unfortunately, surgical face masks are partly made of a plastic material known as polypropylene and take about 450 years for the face mask to decompose. Plastic face masks take 450 years to decompose in nature. Although using a face mask is lifesaving, it could also be life-threatening if not handled properly. It was estimated that a whopping 10 million face masks are used and discarded daily, and many are done indiscriminately. As the country mandates face mask usage, litter contributed by face mask disposal has become a common sight. A few non-governmental organisations (NGOs) have raised their concerns over the issue because it might pollute the environment and pose a threat to wildlife.

Generally, the foreign workers and immigrants had complied with the Malaysian Government's order to practice safe social distances and make it mandatory to wear a face mask when in public. Nonetheless, there are still some discrepancies in how they carried out or followed the Malaysian Government's order.

More than $50 \%$ ( 3 out of 5 ) of the respondents do not know how to use and handle the disposable face mask. They had improperly used the facemask by not ensuring the facemask adequately covering their nose and mouth, placing their mask under their chin. Some of them were using a recycled or a dirty facemask. The findings showed that some foreign workers or immigrant communities do not fully understand the importance of adequately wearing and handling the face mask. There was also an issue with recycling or reusing the disposable face mask among the respondents. Financial constraints mainly contributed to the problems to obtain new face mask stock. It was also found that a handful of advocates do not provide face masks for foreign workers or immigrants working under them.

Secondly, more than $50 \%$ ( 3 out of 5 ) of the respondents also do not know how to remove, handle, and dispose of the used disposable face mask. They do not understand that removing and disposing of the face mask involves clean hands, where the importance of hand hygiene was unknown to them. As a result, some had arbitrarily removed and disposed of face masks everywhere, ignoring the harmful health effect of such action.

The findings further reflect that the community was inattentive of face mask pollution's current environmental hazard issue. For example, it was unknown to them that the disposable face mask takes time to decompose. Besides, they did not recognise the disposable face mask as medical waste, which, if reused or recycled, increases the chance of virus transmission given inefficacious respiratory protection.

Finally, it was observed that almost all (4 out of 5 ) of the respondents have difficulties understanding the language usually spoken in Malaysia. This will lead to whether they know what the Government and media are trying to convey regarding proper procedures in combating the pandemic in Malaysia. The immigrant's inability to understand what the Malaysian Government tried to convey may have resulted in the findings during this sharing session. 


\section{Recommendations}

Based on the findings during knowledge sharing with the immigrants, the recommendations may include:

\section{To Create Face Mask Policy}

Elicited from the research findings, the foreign workers and immigrants did not know the proper way of using the face mask. Hence it is recommended that the employer who employed the foreigners to work in construction sites, in factories and others should create a face mask policy in which they should make it compulsory for all the workers to always wear face masks properly. The employer also needs to make the top management understand the importance of wearing disposable masks during the pandemic. The administration needs to allocate a budget in purchasing disposable face masks and provide it to their employees. Buying the face masks and mandating their use is a way to make sure everyone stays healthy.

Reusable and eco-friendly facemasks appear to be an adequate solution in helping to reduce their potential environmental impact and the quantity of facemasks used and generated daily. It is also noteworthy for recycling face masks into biofuel, ethanol, steam, and electricity to combat the increasing amount of face masks waste in nature, including rivers and oceans.

\section{To Communicate the Policy}

Since the foreign workers do not fully understand the importance of adequately wearing and handling the disposable face mask, the employer should communicate the policy. Once the management understands the policy, it is time to explain it to employees. It is the employer's responsibility to make sure the safety of their workers. Hence, along with requiring employees to wear face masks, the employer also needs to explain the right way to wear disposable face masks and how to dispose of used face masks.

\section{To Use Simple Language}

To overcome the language barrier, it is suggested that instead of using verbal explanation, the government can practically demonstrate the correct way of handling the mask and ask the immigrants to re-demonstrate to make sure they understand the information given. By doing this, two-way communication can be established, and it is a more effective method. With regards to the role of employers, they should be responsible for making sure the immigrants' workers understand the standard operating procedure outlined by the Malaysian Government to curb the COVID-19 infections. The language barrier should be eliminated by taking full responsibility to educate the immigrants' workers.

\section{To Listen and To Understand}

The employer should engage with their employee and understand their problem regarding wearing face masks while working. For example, some people may not only feel that wearing a mask is uncomfortable, but they may also be claustrophobic. Just listening to their feelings about wearing a face mask may help boost compliance. It is said that the best way to deal with people who aren't wearing their masks or are wearing them incorrectly is for the employer to calmly bring it to their attention and ask questions about what's keeping them from complying with the face mask mandate. Whatever it is, understanding the employee is the key. 


\section{Conclusion}

This study analyses Malaysian community attitudes toward using and disposing of face masks and the potential environmental impact of improper use and management of this type of item through a public survey analysis. The study reveals that the number of face masks used during the COVID-19 pandemic. Results will help to understand the fundamental inside knowledge of mask waste generation. These additionally enhanced face masks containing plastic contributed to micro-plastic pollution in the aqua environment and significantly impacted the soil. A detailed study was therefore carried out to identify the legal awareness of the public on the face masks disposal and preventive measures.

Furthermore, this paper highlighted the sustainable approach of disposing of, collecting, selecting, and sorting face masks is still a big challenge to Malaysia as it is common to all types of solid waste. The survey and analysis results revealed that users' behaviour concerning the use and management of facemasks has a significant impact on environmental impacts. The improper disposal of face masks is due to a lack of knowledge and awareness. Thus, changing public attitudes toward the use and disposal of plastic waste, such as facemasks and installing efficient and functional waste management facilities in urban areas, will help reduce plastic waste during the pandemic and afterwards.

\section{References}

Abazah, S., Bong, D., Lee, J., May, N. (2019). Microplastic pollution: A macro problem. UMLawreview. Retrieved 2021, January from https://www.umlawreview.com/lex-inbreve/microplastic-pollution-a-macro-problem

Asian countries by population (2021), Woldometer. Retrieved 2021, September from https://www.worldometers.info/population/countries-in-asia-by-population/

Asmuni, S., Hussin, N. B., Khalili, J. M., \& Zain, Z. M. (2015). Public participation and effectiveness of the no plastic bag day program in Malaysia. Procedia - Social and Behavioral Sciences, 168, 328-340. https://doi.org/10.1016/j.sbspro.2014.10.238

Bedi, R. S. (2020). Health ministry detects five 'generations' of COVID-19 cases linked to tabligh cluster. Thestar. Retrieved 2021, June, from https://www.thestar.com.my/news/nation/2020/03/27/health-ministrydetects-five-039generations039-of-covid-19-cases-linked-to-tabligh-cluster

British High Commission Kuala Lumpur. (2019). UK and Malaysia join hands in tackling plastic pollution. Retrieved 2021, March from https://www.gov.uk/government/news/ukand-malaysia-join-hands-in-tackling-plastic-pollution

Carbon, C. C. (2021). About the acceptance of wearing face masks in times of a pandemic. iPerception, Vol. 12(3), 1-14. https://doi.org/10.1177/20416695211021114

Carlini, G., \& Kleine, K. (2018). Advancing the international regulation of plastic pollution beyond the United Nations Environment Assembly resolution on marine litter and microplastics. Review of European, Comparative \& International Environmental Law, 27(3), 234-244.

Chu, D. K., Akl, E. A., Duda, S., Solo, K., Yaacoub, S., \& Schunemann, H. J. (2020). Physical distancing, face masks, and eye protection to prevent person-to-person transmission of SARS-CoV-2 and COVID-19: A systematic review and meta-analysis. Lancet 2020; 395: 1973-87, Vol. 395. https://doi.org/10.1016/ S0140-6736(20)31142-9 
Citizens Journal Malaysia. (2018). Zero waste programme for 80 klang valley schools. Citizens Journal. Retrieved 2021, January from https://cj.my/112077/zero-waste-programmefor-80-klang-valley-schools/

Fadare, O. O., \& Okoffo, E. D. (2020). Covid-19 face masks: A potential source of microplastic fibers in the environment. Science of The Total Environment, 737. https://doi.org/10.1016/j.scitotenv.2020.140279

Finska, L., \& Howden, J. G. (2018). Troubled waters - where is the bridge? Confronting marine plastic pollution from international watercourses. Review of European, Comparative and International Environmental Law, 27(3), 245-253. https://doi.org/10.1111/reel.12257

Habibu, S., \& Rahim, R. (2020). More relaxation on public activities. The Star. Retrieved 2021, December from https://www.thestar.com.my/news/nation/2020/06/08/morerelaxation-on-public-activities

Kampf, G., Todt, D., Pfaender, S., \& Steinmann, E. (2020). Persistence of coronaviruses on inanimate surfaces and their inactivation with biocidal agents. Journal of Hospital Infection, Vol. 104(3), 246-251.

Malaysia confirms first cases of coronavirus infection. (2020). Retrieved 2020, April 7 from: https://www.reuters.com/article/china-health-malaysia/malaysiaconfirmsfirst-cases-of-coronavirus-infection-idUSL4N29U03A

Malaysia records first two COVID-19 deaths; cases soar to 673. (2020). New Straits Times. Retrieved 2021, March from: https://www.nst.com.my/news/nation/2020/03/575451/malaysia-recordsfirst-two-covid-19-deaths-cases-soar-673

Sangkham, S. (2020). Face mask and medical waste disposal during the novel COVID-19 pandemic in Asia. Case Studies in Chemical and Environmental Engineering 2, Vol. 2. https://doi.org/10.1016/j.cscee.2020.100052

Torres, F. G., \& Torre, G. E. (2021). Face mask waste generation and management during the COVID-19 pandemic: An overview and the Peruvian case. Science of The Total Environment, Vol. 786. https://doi.org/10.1016/j.scitotenv.2021.147628. 